\title{
In vitro Efficacy of Fungicides against Alternaria brassicicola Causing Alternaria Leaf Spot of Cabbage
}

\author{
G.V.N.S.M. Kiran*, S.S. Thara and G.B. Brinda \\ Department of Plant Pathology, College of Agriculture, Vellayani, Kerala Agricultural \\ University, India \\ *Corresponding author
}

\section{A B S T R A C T}

Keywords

Alternaria

brassicicola, In

vitro, Poisoned food technique

Article Info

Accepted:

10 March 2018

Available Online:

10 April 2018
Cabbage [Brassica oleracea var capitata (L.)] is an economically important cool season vegetable crop belongs to family Cruciferae. Alternaria leaf spot of cabbage caused by Alternaria brassicicola is the most destructive disease causing significant yield losses every year. In vitro evaluation were done with fungicides including the new generation viz., propiconazole, hexaconazole, tebuconazole, azoxystrobin each at three different concentrations $(0.05 \%, 0.1 \%, 0.2 \%)$ and propineb, mancozeb, copper oxychloride at $0.1 \%$, $0.2 \%$ and $0.4 \%$ concentrations respectively against the pathogen using poisoned food technique. The results revealed that propiconazole, hexaconazole, tebuconazole and copper oxychloride completely inhibited the mycelial growth of pathogen followed by mancozeb $(0.1 \%)$, propineb $(0.1 \%)$ and azoxystrobin $(0.1 \%)$ by $51.1 \%, 50 \%$ and $27.7 \%$ respectively.

\section{Introduction}

Cabbage is the most popular cool season vegetable crop cultivated all over the world belongs to the family Cruciferae. The economic part of cabbage is head formed by overlapping of thick leaves around the terminal bud. The weight of head is about 0.5 $-4 \mathrm{~kg}$.

Cabbage is an important source of vitamin $\mathrm{C}$, Vitamin K, Vitamin B6 and folate. Apart vegetable crop it is consumed in different forms i.e., pickling, soups and sauerkraut. It has anti-inflammatory and anti-ageing properties.
The total production of cabbage was 71.8 metric tonnes in the world. China is the largest producer of cabbage with 33.4 million tonnes followed by India with nine million tonnes. The crop has been originated from mediterrenean regions.

As the economic part of cabbage is head, Alternaria leaf spot caused by Alternaria brassicicola becomes an emerging and widespread disease affecting the production of crop from seedling to harvest stage. Initially dark lesions are usually seen on leaf enlarges and develop concentric zonations. These lesions will coalesce together and thereby defoliation occurs (Dillard et al., 1997). 
The best way to combat the disease is by utilization of high yielding resistant varieties. In absence of this resistant variety usage of fungicides was an alternate strategy to tackle the disease.

Thereby the present study were undertaken to determine the efficacy of fungicides under in vitro, so it can be used to manage the Alternaria leaf spot of cabbage.

\section{Materials and Methods}

The efficacy of four systemic fungicides i.e., propiconazole, hexaconazole, tebuconazole, azoxystrobin and three contact fungicides i.e., mancozeb, propineb and copper oxychloride were evaluated at three different concentrations against Alternaria brassicicola using poison food technique (Nene and Thapliyal, 1982).

For this, double strength potato dextrose agar medium is used. $50 \mathrm{ml}$ of double strength PDA medium and $50 \mathrm{ml}$ of distilled water was poured in separate conical flasks and sterilized in an autoclave. The fungicide was mixed in sterile distilled water and swirled well. Then fungicide suspension was poured into melted and cooled PDA medium and properly agitated to get uniform suspension.

Then $15 \mathrm{ml}$ of poisoned medium was poured into sterilized petriplates under aseptic conditions and allow to solidify it. Five mm disc cuts were taken from actively growing seven days old culture plate by using cork borer and inoculated at the centre of petriplate containing poisoned medium. Inoculating the pathogen at the centre of petriplate on PDA without poisoning serve as control. Three replications were maintained for each treatment and plates were incubated at room temperature $25 \pm 2^{0} \mathrm{C}$. Observations on colony diameter were taken when the pathogen grown full in the control plate.
The per cent inhibition of mycelial growth of pathogen over control was calculated by using the formula (Vincent, 1947)

$\mathrm{I}=\frac{\sqrt{0-\sqrt{2}}}{\mathbb{a}} \times 100$

Where,

$\mathrm{I}=$ Per cent inhibition of the pathogen

$\mathrm{C}=$ Pathogen growth in control plate

$\mathrm{T}=$ Pathogen growth in treatment plate

\section{Results and Discussion}

Efficacy of four systemic fungicides was evaluated at three different concentrations $0.05 \%, \quad 0.1 \%, \quad 0.2 \%$ against Alternaria brassicicola. The result revealed that all the triazoles i.e., propiconazole, tebuconazole, hexaconazole completely inhibited the growth of pathogen which were significantly on par each other and least inhibition by azoxystrobin $(27.7 \%, 31.1 \%, 33.3 \%)$ at $0.05 \%, 0.1 \%$ and $0.2 \%$ concentrations (Table 1 ).

$\mathrm{Tu}$ and Somasekhara (2015) reported that the growth of Alternaria brassicicola is completely inhibited by the fungicides propiconazole and tebuconazole.

Singh and Singh (2006) reported that the fungicide hexaconazole shown $100 \%$ inhibition of the pathogen Alternaria alternata, the incitant of alternaria blight of tomato.

Ginoya and Gohel (2015) reported that tebuconazole and hexaconazole completely inhibited the mycelial growth of Alternaria alternata in chilli. Surviliene and Dambrauskiene (2006) tested the efficacy of strobilurin fungicides against Alternaria dauci and revealed that the percentage of inhibition was $13.33 \%$ with azoxystrobin and $14.44 \%$ with trifloxystrobin. 


\section{Systemic fungicides}
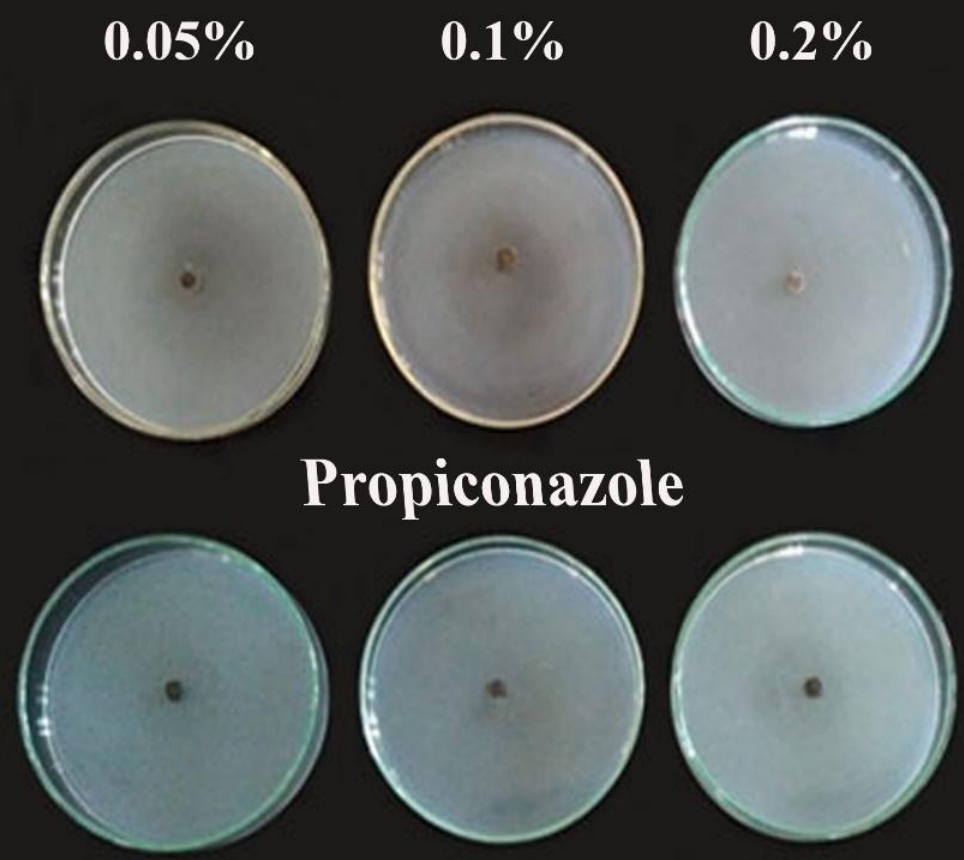

Hexaconazole
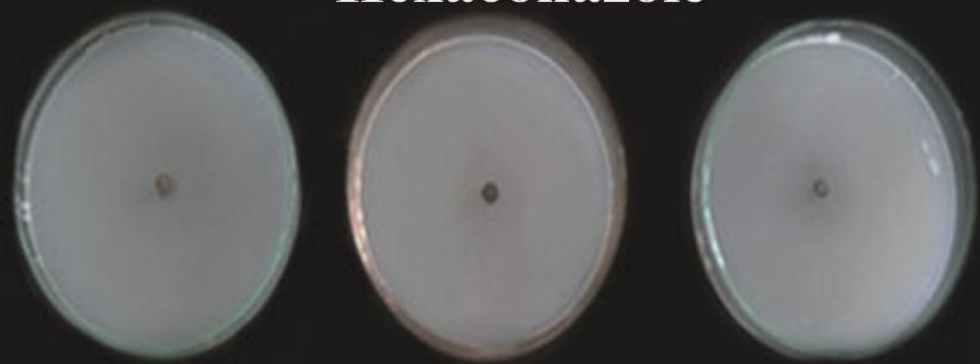

Tebuconazole

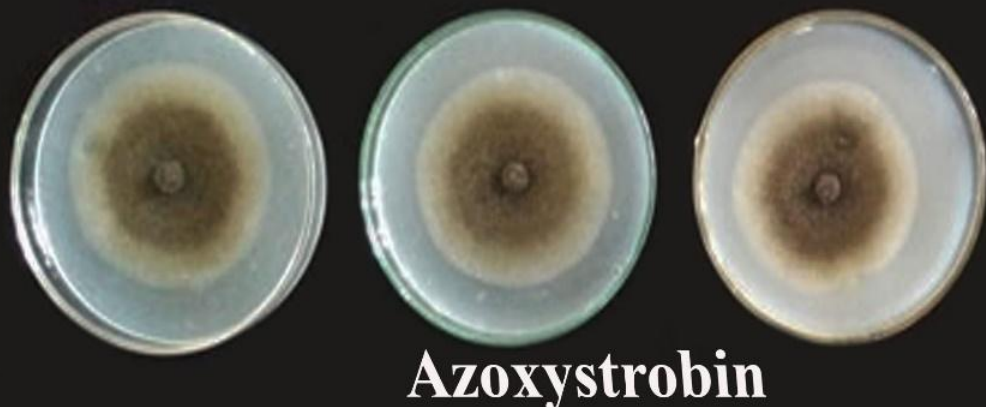




\section{Contact fungicides}
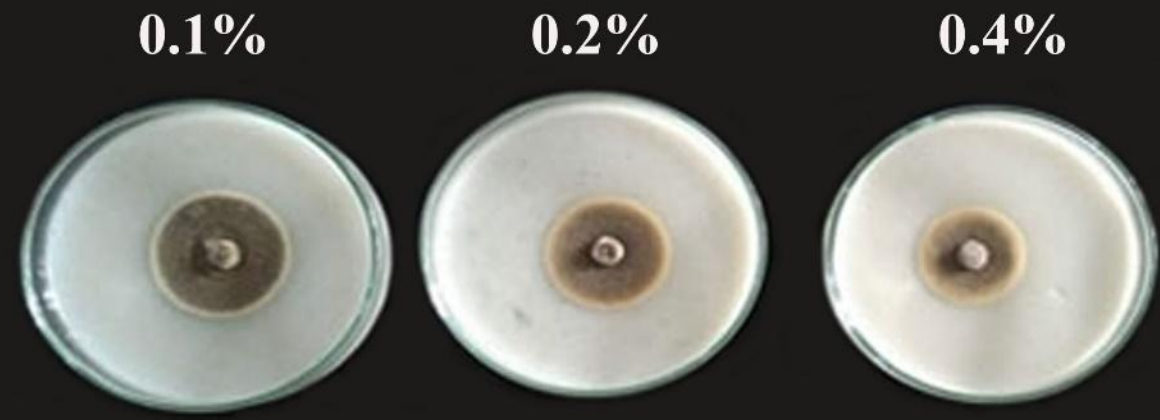

\section{Propineb}
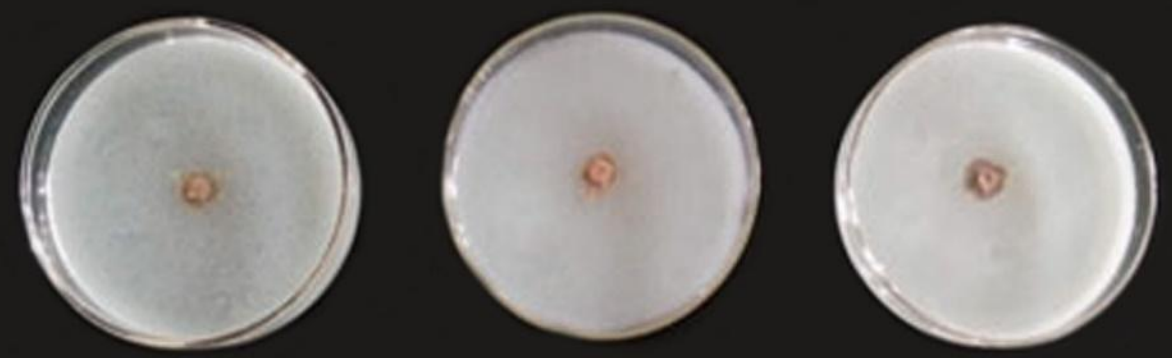

Copper oxychloride
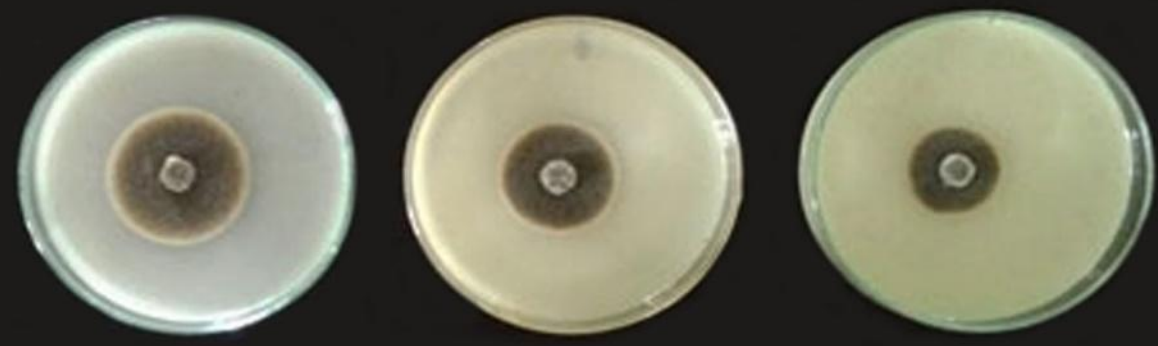

Mancozeb

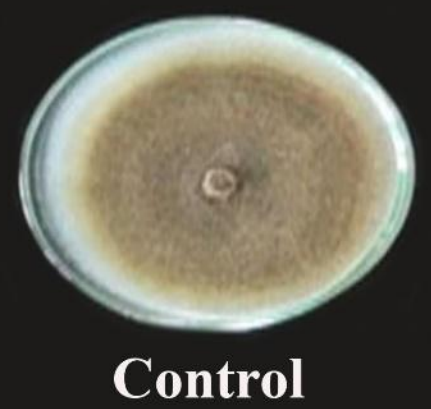


Table.1 In vitro efficacy of fungicides against A. brassicicola

\begin{tabular}{|c|c|c|c|c|}
\hline \multirow[t]{2}{*}{ Fungicide } & \multicolumn{3}{|c|}{ Per cent inhibition of mycelial growth } & \multirow[t]{2}{*}{ Mean } \\
\hline & $0.05 \%$ & $0.1 \%$ & $0.2 \%$ & \\
\hline Propiconazole & $100(89.04)$ & $100(89.04)$ & $100(89.04)$ & 100 \\
\hline Tebuconazole & $100(89.04)$ & $100(89.04)$ & $100(89.04)$ & 100 \\
\hline Hexaconazole & $100(89.04)$ & $100(89.04)$ & $100(89.04)$ & 100 \\
\hline \multirow[t]{2}{*}{ Azoxystrobin } & $27.7(31.75)$ & $31.1(33.89)$ & $33.3(35.24)$ & 30.7 \\
\hline & $0.1 \%$ & $0.2 \%$ & $0.4 \%$ & \\
\hline Propineb & $50(45)$ & $61.1(51.41)$ & $66.6(54.69)$ & 59.23 \\
\hline Copper oxychloride & $100(89.04)$ & $100(89.04)$ & $100(89.04)$ & 100 \\
\hline Mancozeb & $51.1(45.63)$ & $62.2(52.06)$ & $69.96(56.77)$ & 61.08 \\
\hline Mean & 75.54 & 79.2 & 81.40 & 78.71 \\
\hline CD (P 0.01) & 1.421 & 1.754 & 1.775 & \\
\hline S. Em \pm & 0.277 & 0.338 & 0.345 & \\
\hline
\end{tabular}

Values in parenthesis are arc sin transformed.

Of the three contact fungicides tested at three different concentrations $(0.1 \%, 0.2 \%, 0.4 \%)$ against $A$. brassicicola revealed that mycelial growth was completely inhibited with copper oxychloride followed by mancozeb $(51.1 \%$, $62.2 \%, 69.96 \%)$ and least inhibition with propineb $(50 \%, 61.1 \%, 66.6 \%)$ at $0.1 \%, 0.2 \%$ and $0.4 \%$ concentrations respectively. Ansari et al., (1990) reported that the fungicides Blitox-50, Difoltan-80, Dithane Z-78 and Ziram completely inhibited the growth of Alternaria brassicae.

Based on the above results it was clear that the fungicides propiconazole, hexaconazole, tebuconazole and copper oxychloride were effective against $A$. brassicicola the incitant of alternaria leaf spot of cabbage.

\section{References}

Ansari, N. A., Khan, M. W., and Muheet, A. 1990. Evaluation of some fungicides for seed treatment and foliar application in management of damping-off of seedlings and blight of rapeseed caused by Alternaria brassicae. Mycopathologia, 110(3): 163-167.
Dillard, H. R., Cobb, A.C., and Lamboy, J. S. 1997. Transmission of Alternaria brassicicola in cabbage by flea beetles. Plant. Dis. 82:153-157.

Ginoya, C. M., and Gohel, N. M. 2015. Evaluation of newer fungicides against Alternaia alternate (Fr.) keissler causing fruit rot disease of chilli. Int. J. Plant Prot, 8(1): 169-173

Nene, Y. L., and Thapliyal, P. N. 1982. Fungicides in plant disease control (Ed): Oxford and IBH publishing Co. Pvt. Ltd. New Delhi, pp. 325.

Singh, P. C., and Singh, D. 2006. In vitro evaluation of fungicides against Alternaria alternata. Ann. plant Prot. Sci. 14(2): 500502.

Tu, D. V., and Somasekhara, Y. M. 2015. In vitro and In vivo evaluation of new molecules of fungicides against leaf spot (Alternaria brassicicola (Schw.) Wiltshire) of cabbage (Brassica oleracea var. capitata L.). Mysore J. Agric. Sci., 49(2): 359-363

Vincent, J. M., 1947, Distribution of fungal hyphae in the presence of certain inhibitors. Nature. 159: 850.

\section{How to cite this article:}

Kiran, G.V.N.S.M., S.S. Thara and Brinda, G.B. 2018. In vitro Efficacy of Fungicides against Alternaria brassicicola Causing Alternaria Leaf Spot of Cabbage. Int.J.Curr.Microbiol.App.Sci. 7(04): 1131-1135. doi: https://doi.org/10.20546/ijcmas.2018.704.124 